\title{
Ambient bright light treatment improved proxy-rated sleep but not sleep measured by actigraphy in nursing home patients with dementia: a placebo-controlled randomised trial
}

\author{
Gunnhild J. Hjetland ${ }^{1,2,3^{*}}$ (D), Eirin Kolberg ${ }^{1}$, Ståle Pallesen ${ }^{4,5}$, Eirunn Thun ${ }^{1,5}$, Inger Hilde Nordhus ${ }^{1,6}$,
} Bjørn Bjorvatn ${ }^{4,7}$ and Elisabeth Flo-Groeneboom ${ }^{1}$

\begin{abstract}
Background: Up to $70 \%$ of nursing home patients with dementia suffer from sleep problems. Light is the main zeitgeber to the circadian system and thus has a fundamental impact on sleep-wake behaviour. Low indoor light levels in nursing homes have been reported, and in combination with age-related reductions in light sensitivity, insufficient light exposure is likely to contribute to sleep problems in this population. Increasing daytime light exposure using bright light treatment (BLT) may represent a feasible non-pharmacological treatment for sleep problems in nursing home patients with dementia.
\end{abstract}

Methods: The present study reports on sleep outcomes, which are the primary outcomes of the DEM.LIGHT trial (Therapy Light Rooms for Nursing Home Patients with Dementia- Designing Diurnal Conditions for Improved Sleep, Mood and Behavioural Problems), a 24-week cluster-randomised placebo-controlled trial including 8 nursing home units and 69 resident patients. The intervention comprised ambient light of $1000 \mathrm{~lx}$ and $6000 \mathrm{~K}$ from 10:00 to 15:00, with gradually increasing and decreasing light levels prior to and following this interval, using ceiling mounted light-fixtures and light emitting diode technology. The placebo condition had continuous standard light levels (150-300 lx, $3000 \mathrm{~K}$ ). Sleep was assessed at baseline and follow-up at week 8, 16, and 24, using the proxy-rated Sleep Disorder Inventory (SDI) and actigraphy (Actiwatch II, Philips Respironics). Mixed linear models were used to evaluate intervention effects, adjusting for relevant covariates such as age, gender, number of drugs, severity of dementia, eye disease, and estimated light exposure.

\footnotetext{
* Correspondence: Gunnhildjohnsen.Hjetland@fhi.no

'Department of Clinical Psychology, Faculty of Psychology, University of Bergen, Bergen, Norway

${ }^{2}$ City Department of Health and Care, City of Bergen, Norway

Full list of author information is available at the end of the article
}

(c) The Author(s). 2021 Open Access This article is licensed under a Creative Commons Attribution 4.0 International License, which permits use, sharing, adaptation, distribution and reproduction in any medium or format, as long as you give appropriate credit to the original author(s) and the source, provide a link to the Creative Commons licence, and indicate if changes were made. The images or other third party material in this article are included in the article's Creative Commons licence, unless indicated otherwise in a credit line to the material. If material is not included in the article's Creative Commons licence and your intended use is not permitted by statutory regulation or exceeds the permitted use, you will need to obtain permission directly from the copyright holder. To view a copy of this licence, visit http://creativecommons.org/licenses/by/4.0/. The Creative Commons Public Domain Dedication waiver (http://creativecommons.org/publicdomain/zero/1.0/) applies to the data made available in this article, unless otherwise stated in a credit line to the data. 
(Continued from previous page)

Results: Sleep as measured by the SDI was significantly improved in the intervention group compared to the control group from baseline to week $16(B=-0.06,95 \% \mathrm{Cl}-0.11--0.01, p<.05)$ and from baseline to week $24(\mathrm{~B}=$ $-0.05,95 \% \mathrm{Cl}-0.10--0.01, p<.05)$. There was no effect according to the SDI at week 8 and no significant effects in terms of actigraphically measured sleep.

Conclusions: Proxy-rated sleep improved among nursing home patients with dementia following 16 and 24 weeks of BLT. These improvements were not corroborated by actigraphy recordings.

Trial registration: ClinicalTrials.gov Identifier: NCT03357328. Registered 29 November 2017 - Retrospectively registered.

Keywords: Sleep, Dementia, Nursing home, Actigraphy, Sleep disorder inventory

\section{Background}

Dementia denotes a group of disorders characterised by progressive neurodegenerative and/or vascular damage, with accompanying impairments of cognition and disturbances of mood and behaviour [1]. These disorders constitute a severe burden at the individual and societal level [2], making them a social health priority of the World Health Organization [3].

Disrupted sleep constitutes a major challenge in relation to dementia, as it affects up to $70 \%$ of the patients [4]. As sleep is essential for normal functioning, its disruption may have severe negative effects on cognitive, emotional, and physical functioning [5]. In the context of cognitive impairment, sleep disruption places a significant burden on caregivers [6]. Related events such as night-time wandering and confusion may increase the risk of falls and injuries [7, 8]. Importantly, sleep problems are associated with increased depressive symptoms [9-11], reduced functional status (ability to perform normal daily activities) [12], and cognitive decline [13]. Due to limited staff in nursing homes, pharmacological treatment (e.g., antidepressants, benzodiazepines, zhypnotics, and antipsychotics) are often resorted to for relieving sleep disturbances [14]. Medications are, however, often associated with side-effects such as sedation and risk of falling $[14,15]$, and there is generally limited evidence for their efficacy in these populations [16]. Thus, identifying safe and effective treatments for disturbed sleep is of crucial importance.

As dementia progresses, brain systems involved in sleep-wake regulation are increasingly affected $[5,17]$. Importantly, this includes neurodegeneration of the suprachiasmatic nucleus (SCN) of the hypothalamus, the main circadian pacemaker, which generates 24-h rhythms in hormone levels, body temperature, and sleep-wake behaviour. As a result, people with dementia often display a fragmented sleep pattern with several sleep and wake periods occurring throughout the 24-h day $[17,18]$. Disrupted sleep may be further worsened by factors such as reduced social interaction, inactivity, and medications $[19,20]$. In addition, light exposure plays a major role in circadian regulation, and insufficient exposure has consequently been associated with sleep problems in dementia patients [21, 22].

Light is detected by the intrinsically photosensitive retinal ganglion cells of the eye (ipRGCs; neurons in the retina containing the light sensitive photopigment melanopsin) and relayed directly to the SCN. The effects of light exposure on the circadian system depend on the timing, duration, illumination level (lux), and spectral composition (i.e., the colour of the light), as well as light exposure history [23]. The ipRGCs are maximally sensitive to short wavelengths $(\sim 480 \mathrm{~nm})[24,25]$, hence polychromatic light with high amounts of short wavelengths, i.e., blue light, therefore elicits stronger circadian responses than light with large amounts of long wavelengths (red-yellow) [26, 27]. The colour appearance of light is defined by correlated colour temperature (CCT), measured in Kelvin (K). Daylight has a large amount of blue light, with a CCT of about 5700-7700 K, depending on atmospheric conditions [28]. In comparison, standard light bulbs typically deliver more yellow light, with lower CCT (2700-3000 K).

With increasing age, lens yellowing and excessive pupil constriction (senescent miosis) reduce the amount of light reaching the retina $[29,30]$. Although some evidence has suggested compensatory mechanisms preserving light sensitivity [31], lens yellowing has been associated with self-reported sleep disturbances [32]. Further, Alzheimer's disease is associated with several pathological changes in the visual system, including loss of ipRGCs [33]. Several studies have reported light levels in nursing homes far below what is considered necessary for circadian entrainment (synchronising of an organisms' rhythms to recurring environmental cues) [17, 3437]. For example, in a study of seven nursing homes in the Netherlands, Sinoo et al. [37] found that $65-96 \%$ of the light measurements fell below $750 \mathrm{~lx}$. In a recent study including 15 Norwegian dementia unit living rooms [38], median vertical illumination was below 300 $\mathrm{lx}$, even in summer. In contrast, daylight ranges from 6500 to $130,000 \mathrm{~lx}$ depending on weather conditions [39, 
40]. In sum, age and dementia-related changes to the eye and low indoor illumination in relevant institutions suggest that dementia patients are rarely exposed to light levels sufficient to entrain the circadian clock. Therefore, increasing light exposure, i.e., bright light treatment (BLT), constitutes a promising non-pharmacological treatment for disrupted sleep in people with dementia.

Traditionally, BLT has been administered using light boxes with high illumination white light (2500-10,000 lx at distances from 10 to $50 \mathrm{~cm}$ ) for 30 to 120 min each day. This requires the patient to sit relatively still and face the box. Several studies have reported within-group improvements of sleep outcomes using this type of BLT [41-47], although the results are not consistent [48-50]. An issue with light boxes is that dementia patients are in need of continuous supervision to receive sufficient light exposure [42], which is often too demanding for the staff. Recent advances in light emitting diode (LED) technology have allowed for the manipulation of both light illumination and its spectral composition. This technology is able to deliver light of high CCT and illumination and may be used to change the ambient light of entire rooms. Researchers have in this realm typically used light ranging from $6500 \mathrm{~K}$ and $1200 \mathrm{~lx}$ to $13,000 \mathrm{~K}$ and $400 \mathrm{~lx}$ [51]. By this way of administering light, the patients may move around freely, and the need for staff to ensure treatment adherence is eliminated. In addition, such systems may be programmed to provide light contrasts between midday (high illumination short wavelength light) and early mornings and evenings (lower illumination and "warmer", longer wavelength light).

Although BLT has been evaluated as a treatment for sleep problems and emotional and behavioural symptoms in dementia populations for two decades, conclusive results about its efficacy are lacking. Recent meta-analyses, with 6 to 11 studies included, have reported only small effects (Hedges' $g$ of $0.25-0.30$ ) of BLT in dementia [52, 53]. Generally, few randomised controlled trials have been conducted and there are considerable variations in methods and designs, such as the timing, duration, and means of delivering BLT. Hence, there is a need for more high-quality studies [51].

In the present study we report the primary outcomes from the DEM.LIGHT trial aiming to evaluate the effects of a ceiling-mounted dynamic ambient BLT solution on sleep in nursing home patients with severe dementia. We hypothesised that the BLT condition would improve sleep measured by actigraphy and a proxy-rated sleep scale across the 24-week treatment period, as compared to a control group receiving conventional light with standard and constant light levels.

\section{Methods}

The present paper is based on data from the 24-week cluster randomised placebo-controlled trial "Therapy
Light Rooms for Nursing Home Patients with DementiaDesigning Diurnal Conditions for Improved Sleep, Mood and Behavioural Problems", the DEM.LIGHT trial (ClinicalTrials.gov Identifier: NCT03357328). This trial evaluated the effect of a BLT solution on sleep, circadian rhythmicity, mood, behaviour, and function in nursing home patients with dementia. The present paper reports on the sleep outcomes of the DEM.LIGHT trial. The other outcomes will be reported in subsequent papers. The DEM.LIGHT trial was conducted from late September 2017 to early April 2018, in Bergen, Norway $\left(60^{\circ} 3^{\prime} \mathrm{N}\right.$, $\left.5^{\circ} 3^{\prime} \mathrm{E}\right)$. The intervention period lasted for 24 weeks and data were collected at baseline, week 8 , week 16 , and week 24 . The present study adheres to the CONSORT guidelines [54].

\section{Participants}

The Department of Health and Care, City of Bergen, Norway, supported the study by providing information about eligible nursing home dementia units (i.e., nursing homes not involved in other trials or quality of care projects, and where ceiling light instalment was possible). The management of eligible nursing homes was contacted by the two researchers leading the data collection (GJH, EK). Site visits were conducted to provide information about the study and assess if light instalment was possible. In total, 14 nursing homes were approached, of which 8 units from eight nursing homes were included. Nursing home units and patients were recruited between September 2016 and August 2017. The eligibility criteria were discussed with the resident medical practitioner of each nursing home before all the eligible patients at the unit were invited to participate. Inclusion criteria were as follows: The patient had to be 60 years of age or older, in long-term care ( $>4$ weeks), have dementia in accordance with DSM-5 criteria and either sleep/circadian rhythm disturbances, BPSD, or severely reduced activities of daily living. Exclusion criteria were blindness or other reasons the patient was unable to benefit from light; the patient was taking part in another trial; a condition that contra-indicated the intervention; an advanced, severe medical condition and/or expected survival of less than 6 months; psychosis or a severe mental disorder; or other aspects that could interfere with participation. Due to the long follow-up of 6 months, it was not possible to maintain stable doses of medications during the course of the study. The number of psychotropic medications were, however, controlled for in the analyses.

\section{Procedures}

\section{The intervention}

A LED ceiling-mounted bright light solution, delivered by Glamox AS (supplier of professional lighting 
solutions), was installed in the common rooms of the four intervention units. Glamox engineers calculated the number of LED units needed in each common room (Glamox, 1 x C95 48 CCT $6500 \mathrm{~K} \mathrm{MP} 47 \mathrm{~W} / 4702$ lm), accounting for the number and direction of windows. The light panels were programmed to provide a cycle of gradually higher illumination and CCT during the day and then lower illumination and CCT in the evening (see Fig. 1), with the highest light levels of 1000 vertical lux and $6000 \mathrm{~K}$ from 10:00 to 15:00. The light equipment was installed prior to the start of the study and light levels were maintained at standard levels (approximately $100 \mathrm{~lx}$ and $3000 \mathrm{~K}$ ) before the study commenced so that staff and participants were familiarised with the new light units. The intervention light sequence was activated following baseline data collection. The control panel for the light was locked with a personal identification number only known to the researchers. The contact information of the researchers was provided in case of any problems with the light setup.

The placebo control condition was created by replacing the light bulbs in the existing fittings with conventional $3000 \mathrm{~K}$ light bulbs in all common rooms (CFL AURA UNIQUE-D/E LL $18 \mathrm{~W} / 830 \mathrm{G} 241-2$ in three common rooms and CFL AURA UNIQUE-L LL $18 \mathrm{~W} /$ $8302 \mathrm{G} 11$ in one), thus largely maintaining the preexisting light levels in these units. These light bulbs were installed immediately following the baseline data collection. After the intervention was activated and the placebo lights were installed, the daytime light levels were measured by the researchers in all eight common rooms using the GL Spectis $1.0 T$ Flicker spectrometer (GL Optic). Spectral analysis was performed in GL Spectrosoft. Vertical measurements were recorded to approximate corneal illumination $(120 \mathrm{~cm}$ above the floor), and horizontal measurements were recorded at the typical height of reading or other visual tasks $(80 \mathrm{~cm}$ above the floor). Effective illuminances were calculated according to the $\alpha$-opic illuminance model using the irradiance toolbox by Lucas et al. [55].

\section{Outcomes}

All questionnaires used in the present study were completed by daytime nursing staff that knew the patients well, i.e., regular staff working directly with the patients. Research staff involved in the DEM.LIGHT trial guided the nurses in using the assessment tools. The questionnaires were completed once at each data collection time point: either the same week the patients wore the actigraphs or the following week. Data regarding sociodemographic characteristics, diagnoses, and medication status were collected from medical records. One of the researchers was granted access to extract these data from a centralised journal system used in nursing homes by Bergen Municipality.

\section{Sleep outcomes}

Changes in sleep parameters comprised the primary outcome of the DEM.LIGHT trial. Sleep was proxy-rated by the nursing staff using the Sleep Disorder Inventory (SDI) [12]. The SDI assesses seven symptoms that are scored in terms of frequency (0-4), severity (0-3), and caregiver distress (0-5). The SDI total score was calculated as the sum of the products of the frequency and severity ratings of each of item 1-7 (range: $0-84$ ). The SDI has previously been demonstrated to correspond well to actigraphy outcomes in this population [56], as well as in home-dwelling dementia populations [12]. A total score of five or more indicates the presence of clinically significant sleep disruption [56].

Actigraphs (Actiwatch II, Philips Respironics) were used to provide an objective estimation of sleep. Actigraphs are wrist-worn devices that measure activity continuously over days or weeks [57]. In accordance with previous studies on nursing home patients, the actigraphs were placed on the dominant or most mobile wrist [58-61] as this increases the chances of detecting movement in patients who are often immobile or lethargic. Based on the activity data, each epoch was scored as sleep or wake by the Actiware software, version 6.0.9 (Philips Respironics). The threshold for wakefulness was

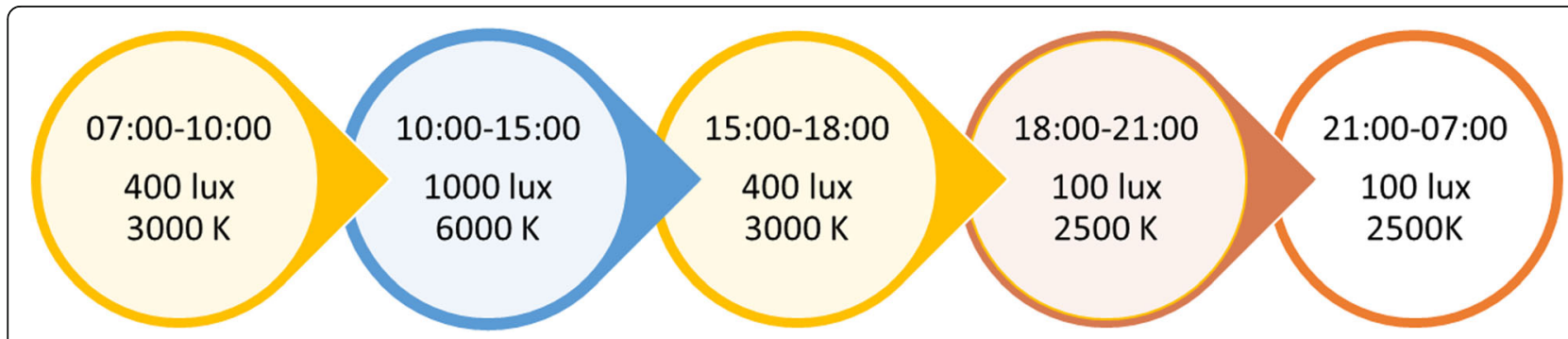

Fig. 1 An illustration of the intervention light sequence. The light changed gradually across 30 min between each condition. Each nursing home could choose if they wanted to turn the lights off or to maintain $100 \mathrm{~lx}$ and $2500 \mathrm{~K}$ throughout the night (21:00-07:00). The patients generally did not spend time in the common room during the night, and whether or not the light was on in the common room depended on the needs of the staff during the night 
set to medium and epoch length to $1 \mathrm{~min}$, as recommended by Camargos et al. [61].

Determining the true bedtime and wake-time in nursing home patients is challenging, as these patients frequently spend more than $12 \mathrm{~h}$ in bed (e.g., $[58,60])$. We initially planned to score the rest intervals based on a predetermined scoring protocol; however, there were rarely clear indications of bedtime and wake time, and the nurses did not consistently press the event buttons. Therefore, a fixed rest interval was set from 22:00 to 06: 00 , in accordance with previous studies, which ensured capturing the main sleep episode of the vast majority of participants [22, 34, 48, 62]. A fixed daytime interval was also set from 10:00 to 18:00. This interval corresponds to other studies in dementia populations, and was chosen to avoid including periods when the participants were in bed [63]. Activity data were collected for seven consecutive days at baseline, and at follow-up after 8, 16, and 24 weeks. Patients had to have at least five nights of recordings to be included in the analyses. The following actigraph outputs were extracted: Sleep efficiency (SE; the percentage of time spent asleep in the rest interval), TST rest (total sleep time in the rest interval), 24-h TST, daytime TST (TST in the daytime interval), and wakeafter-sleep-onset (WASO; the time spent awake after sleep onset) in the rest interval. Since TST rest and SE are perfect linear functions of each other in a fixed rest interval, including both in the analyses would be redundant and TST rest was only used as a descriptive variable.

\section{Other outcomes}

In addition to sociodemographic data, several secondary outcomes were used to describe the population at baseline and as control variables in the analyses. The Mini Mental State Examination (MMSE) assesses the level of cognitive impairment (range: 0-30), where a low score indicates worse cognitive function [64]. The Functional Assessment Staging (FAST) [65] rates the severity of dementia according to seven stages, where a score of 6-7 indicates severe dementia. The Charlson Comorbidity Index (CCI) assigns weights to 17 comorbidities to assess the burden of comorbid disease, where a higher score is associated with a higher mortality risk [66]. To assess activities of daily living (ADL), the instrument by Lawton and Brody was used [67]. This scale includes six items (composite score range $0-30$ ), where a lower value indicates better functioning and independence. The nursing home version of the Neuropsychiatric Inventory (NPI-NH) $[68,69]$ is a proxy-rated tool that assesses "Behavioural and Psychological Symptoms of Dementia" by assigning frequency and severity ratings to $12 \mathrm{symp}-$ toms (delusion, hallucination, agitation, depression, anxiety, euphoria, apathy, disinhibition, irritability, aberrant motor behaviour, night-time behaviour and eating disturbance).

The staff at each unit were urged to report any change in patient health or behaviour in relation to the intervention. Potential adverse events and tolerability were also monitored at each data collection visit.

\section{Adherence to treatment}

To assess adherence to treatment, a questionnaire was administered to the nursing staff, where they were asked to estimate the time each patient spent in the common room during different epochs of the day (average during the last 8 weeks). The epochs corresponded with the light cycle of the intervention, so that the day was split into 07:00-10:00, 10:00-15:00, 15:00-18:00, and "after 18:00". The nursing staff provided a time estimate for each epoch in terms of hours and minutes. They were also instructed to report the number of days when the patient was not present in the common room, and informed that these days should not be included in the above-mentioned estimate. For the purpose of this study, the time estimates corresponding to the epoch with the highest light levels (10:00-15:00) were included in the analyses.

\section{Sample size and power}

Expecting moderate effect sizes (Cohen's $d=.50$ ) for the actigraphy outcomes, a .05 alpha level (two-tailed), and the power set to .80 , the power-analysis showed that 64 participants from a minimum of 8 clusters were needed in order to detect differences between conditions. Expecting a 20\% dropout, the aim was to recruit 80 participants [70, 71].

\section{Randomisation}

After eight nursing home units were included, clusters (each unit constituted one cluster) were randomised to the intervention condition (1) or the control condition (0) using random group assignment in SPSS. Randomisation and enrolment were completed by the research group.

\section{Blinding}

Although the placebo effect might not be an issue in those with severe dementia, staff might be affected, creating bias such as the Hawthorne effect [72, 73]. Hence, potential changes in staff routines and behaviour in response to the treatment may affect outcomes, making a control condition necessary. Because staff and participants could not be kept blind to the intervention, as the light setup comprised an obvious change in the common room, new light bulbs were fitted in the control units to mimic an intervention and ensure similar light levels across the control units. The participants and nursing 
staff were consequently unaware of condition assignment and all included units were located at different nursing homes to minimise threats to internal validity in terms of performance and detection bias [74]. After the end of the trial, the study design was explained to the staff, who were then asked to answer a questionnaire asking whether they thought they were in the control or intervention group.

\section{Statistical analyses}

We initially planned to analyse data using ANOVA, but owing to some missing data due to non-compliance to actigraphy and because some patients passed away or moved to another facility during the study, we evaluated the intervention effects by means of linear mixed models using the lme4 package in $R[75,76]$. This analysis method takes into account all available data, performs better than alternatives when there are missing data, and estimates fixed effects while adjusting for correlation due to repeated measurements on each subject $[77,78]$. Linear mixed models using restricted maximum likelihood estimation were used to assess all outcomes. Group (intervention vs. control), time (treated as categorical with levels baseline, 8 weeks, 16 weeks, and 24 weeks), and the group-by-time interaction were included as fixed effects in the model. The models were fitted with random intercepts at the patient level to account for intra-participant correlation of the outcomes, and random slope was included if model fit improved. Models were selected based on best fit according to likelihood ratio tests.

A range of factors are likely to impact the response to BLT, and a range of predetermined prognostic variables were tested as covariates. AIC and BIC were examined, and likelihood ratio tests were performed using the Anova package in $R$. Furthermore, covariates that improved fit were added to the model. The following list of covariates were tested: Age, gender, number of psychotropic medications, CCI-scores, FAST-scores, MMSEscores, eye disease, whether the patient passed away or moved during the study (drop-out), and average time in the common room during the day (between 10:00 and 15:00). Melanopic lux was also tested as a covariate because the light levels varied within the intervention group (ranging from 675 to 1050 mean vertical melanopic lux) and control group (56 to 261 melanopic lux) (Table S1).

Preliminary analyses showed that the SDI data were highly skewed, consequently the scores were transformed to achieve normal distribution by adding a constant of 0.5 and using a Box Cox transformation, which resulted in a lambda of 0.6.

Further, the relationship between sleep, demographic and secondary outcomes at baseline was investigated by using correlation analysis for continuous data and comparing groups for categorical data using Student's t-test. Differences in light levels between the intervention and the placebo condition, as well as differences in light exposure time were evaluated using Student's t-tests and Mann-Whitney U tests in SPSS for Windows, version 25 (IBM).

\section{Missing data}

If single questionnaires were missing data on $20 \%$ or more of items on the SDI, they were excluded from the analyses. For questionnaires missing less than $20 \%$, and where data were missing completely at random, imputations were made using expectation maximisation (EM) in SPSS.

\section{Results}

Seventy-eight patients were evaluated for eligibility, of which 69 were recruited to the study (see the flow chart in Fig. 2). Figure 3 shows the number of participants included in each analysis at each time point and reasons for missing data (not counting data missing due to death or moving away). Of the 69 patients who were enrolled, the mean age was 84 years, and $68 \%$ were female. The mean MMSE score was 6.4 (SD = 6.7) (Table 1).

Table 2 shows the mean light levels in the intervention and control condition, respectively. All light metrics were significantly higher in the intervention group than the control group (all $p$ 's $<.05$ and Bonferroni adjusted $p<.008)$. The supplemental Table S1 shows the light measurements separately for each unit. There was some variability in light levels across intervention units, and one unit in particular had lower than intended vertical illumination (722; $\mathrm{SD}=69$; photopic lux and 675; $\mathrm{SD}=$ 62; melanopic lux). Also, one control unit had higher illumination than the other control units, with 368 (SD = 99) photopic lux and $261(\mathrm{SD}=125)$ melanopic lux. All other control units had between 134 and 271 photopic lux and between 56 and 143 melanopic lux. Both horizontal and vertical measurements and photopic lux, melanopic lux, and CCT values are provided in Table 2 as well as in supplementary Table S1. Across the intervention period, participants in the intervention group spent a mean of $3 \mathrm{~h}$ and $24 \mathrm{~min}(\mathrm{SD}=1 \mathrm{~h} 30 \mathrm{~min})$, and the control group spent $3 \mathrm{~h}$ and $0 \mathrm{~min}(\mathrm{SD}=1 \mathrm{~h} 42 \mathrm{~min})$ in the common room during the time of day with the highest light levels (10:00-15:00), as estimated by staff (Table 3). There were no significant differences between the groups regarding time spent in the common room at any time point.

The primary outcome of this randomised controlled trial (RCT) was sleep. The linear mixed model analyses for actigraphically measured sleep outcomes showed no statistically significant differences between patients who 


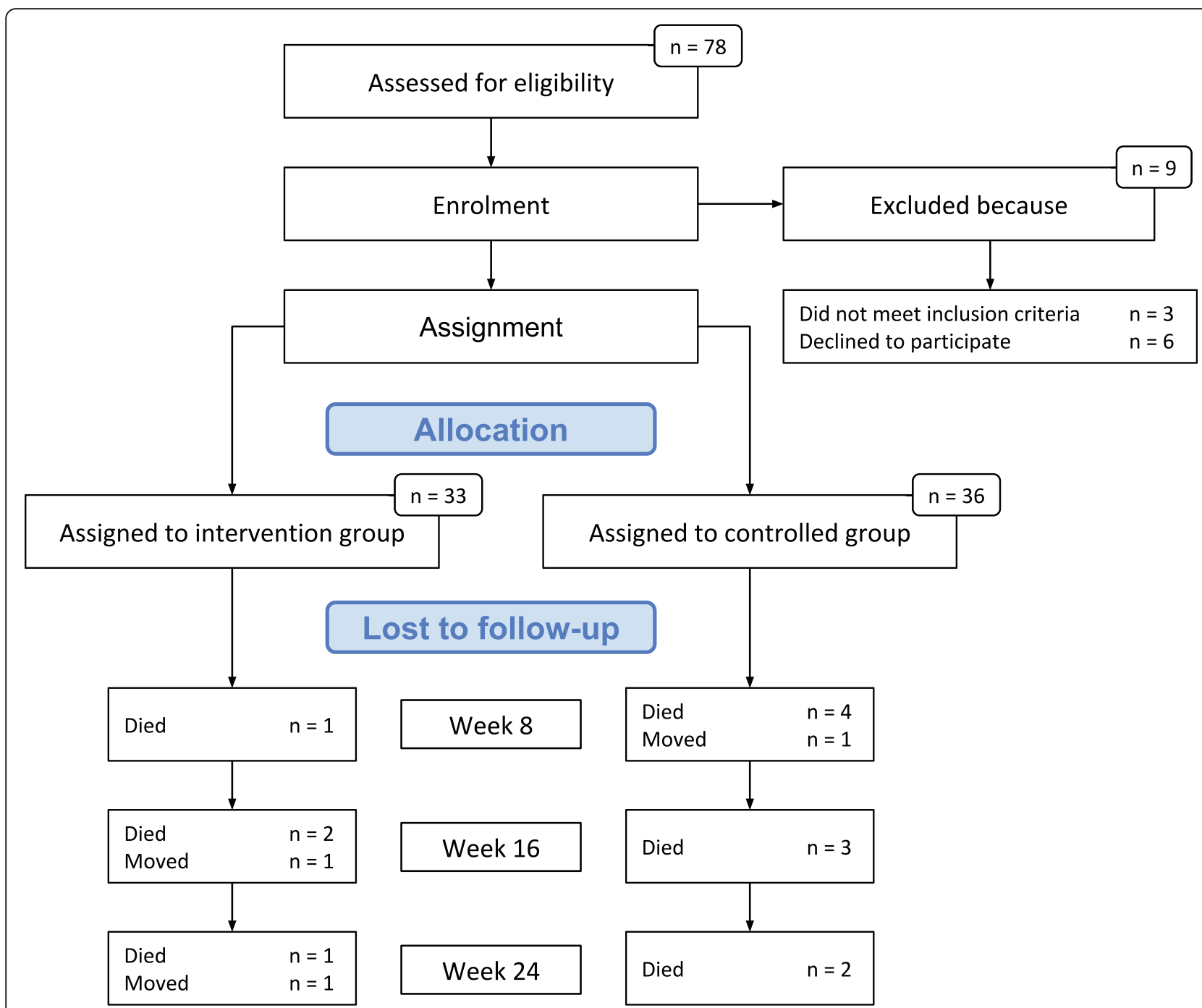

Fig. 2 Showing the flow of participants from eligibility assessment to study completion. Note: Main cause for moving was a deterioration of somatic health requiring the patient to live in a somatic ward

received BLT compared to those who received standard light (see Table 4).

For the SDI, the regression coefficient for the time*group interaction, representing the group difference in change from baseline, was -.06 (95\% CI -.11 to $-.01 ; p=$ $.020)$ at week 16 and -.05 (95\% CI -.10 to $-.01 ; p=.028)$ at week 24 , indicating relatively better sleep in the intervention group (i.e., less disrupted sleep) than the control group at these time points. The average number of psychotropic drugs was included as a covariate in this model. There was no significant effect at week 8 (Table 4).

Table 5 shows the means and standard deviations for the intervention group and the control group for each outcome at each time point, as well as medians and 25th and 75th percentiles for non-normal data.

At baseline, none of the actigraphy sleep parameters correlated with age, total number of drugs, number of psychotropic drugs, number of sedatives, cognitive impairment, dementia severity, or comorbidity (Table 6). The SDI score had significant positive correlations with the total number of medications (Spearman's rho $=.30$, $p=.015)$ and number of psychotropic medications (Spearman's rho $=.35, p=.004$ ). There were no gender differences in sleep outcomes at baseline, in either WASO $(p=.419)$, SE $(p=.622)$, TST day $(p=.154)$, TST $24 \mathrm{~h}(p=.216)$, or SDI $(p=.356)$. Patients with and without eye disease did not differ significantly on WASO $(p=.167)$, TST day $(p=.792)$, TST $24 \mathrm{~h}(p=.098)$ or the SDI $(p=.142)$. However, patients with eye disease had significantly lower SE at night (median of $57 \%$ vs. $80 \%$, $p=.003$ ) than those without eye disease.

No adverse events in relation to the intervention were reported by the staff. There was no significant deterioration of sleep outcomes in the intervention group 


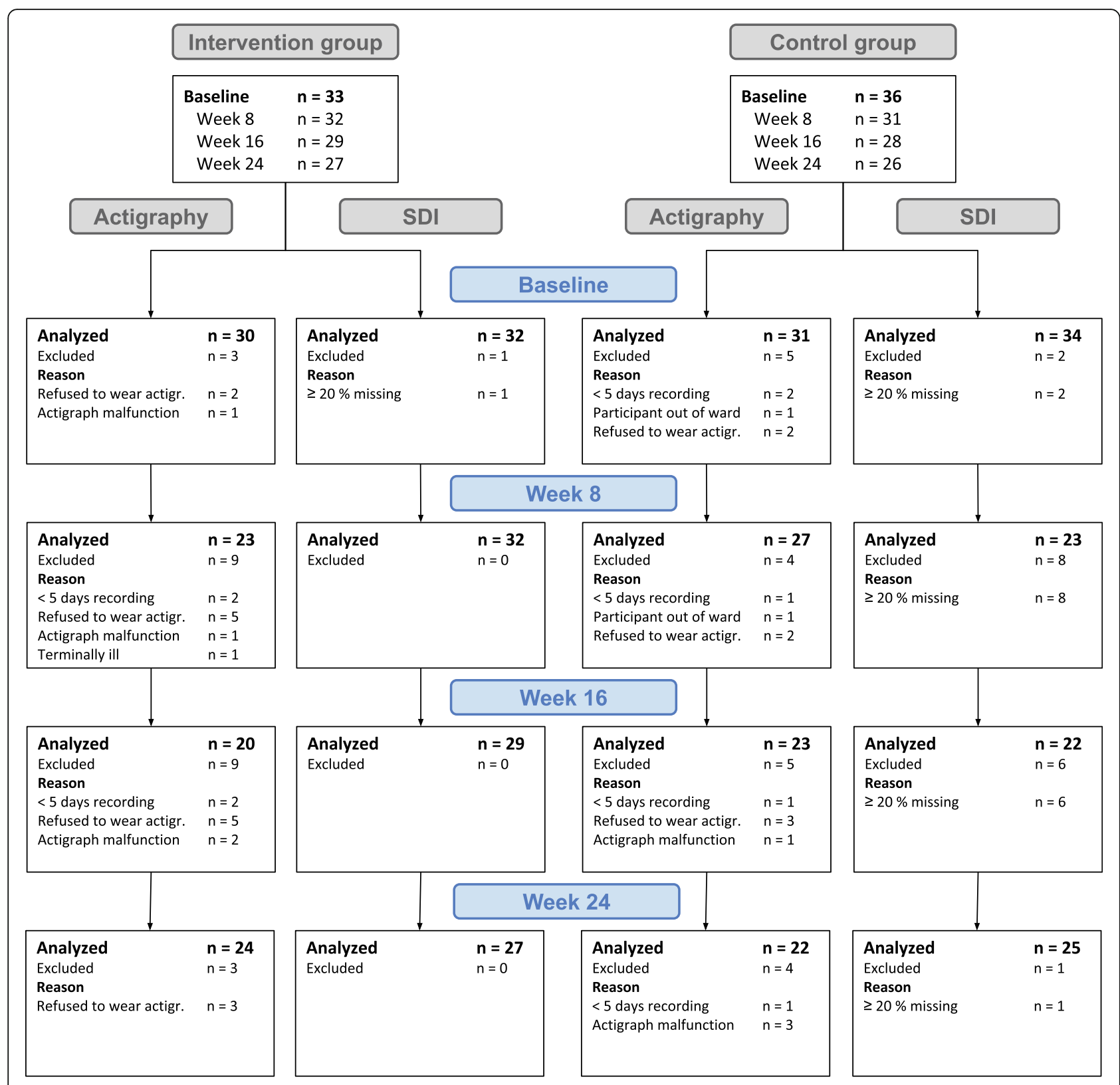

Fig. 3 Overview of missing data and reason for missing at each data collection time point, not including those lost to follow-up

compared to the control group. There were also no negative outcomes in terms of mortality or BPSD other than sleep (not published).

In the intervention group, 5 out of 19 respondents guessed that they were in the control group, and 2 out of 12 respondents in the control group thought that they were in the intervention group.

\section{Discussion}

The present study found no evidence for effects on actigraphically measured sleep following 24 weeks of BLT. However, compared to the control group, the intervention group fared better from baseline to week 16 and from baseline to week 24, as measured by the proxy-rated Sleep Disorder Inventory (SDI). For the SDI, the observed means indicate that the median SDI scores for the control group deteriorated from baseline to week 8 and returned to baseline levels at week 16 and 24, while the intervention group had a slight improvement from baseline to week 24 . These differences were significant at week 16 and 24 in the mixed linear model.

The non-significant findings of the intervention attested to by actigraph data are in line with results based on objective sleep data from some previous RCTs 
Table 1 Descriptive statistics at baseline for the 69 patients

\begin{tabular}{|c|c|c|c|}
\hline & Control group $(n=36)$ & Intervention group $(n=33)$ & Whole group $(n=69)$ \\
\hline Age (mean, SD) & $82.8(7.9)$ & $84.3(6.2)$ & $83.5(7.1)$ \\
\hline Female (\%) & 61 & 76 & 68 \\
\hline MMSE $(n=56)$, median (25th-75th percentile) & $3.0(1.0-7.0)$ & $6.0(2.0-10.0)$ & $4.0(1.0-9.5)$ \\
\hline \multicolumn{4}{|l|}{ Dementia diagnoses, $n(\%)$} \\
\hline$A D$ & $20(55.6)$ & $18(54.5)$ & $38(55.0)$ \\
\hline VD & $2(5.6)$ & $2(6.0)$ & $4(6.0)$ \\
\hline Mixed $A D$ and $V D$ & 0 & 0 & 0 \\
\hline LBD & $1(2.8)$ & 0 & $1(1.5)$ \\
\hline FTD & 0 & 0 & 0 \\
\hline PD & 0 & 0 & 0 \\
\hline Unknown dementia & $10(27.8)$ & $11(33.3)$ & $21(30.5)$ \\
\hline Other dementia & $1(2.8)$ & $1(3.0)$ & $2(3.0)$ \\
\hline No diagnosis ${ }^{*}$ & $2(5.6)$ & $1(3.0)$ & $3(4.0)$ \\
\hline NPI-NH total score $(n=69)$, median (25th-75th percentile) & $12.5(5.5-42.5)$ & $24.0(11.0-42.0)$ & $21.0(6.0-42.0)$ \\
\hline ADL $(n=69)$ (mean, SD) & $18.4(4.7)$ & $17.1(5.1)$ & $17.8(4.9)$ \\
\hline FAST ( $n=67$ ), median (25th-75th percentile) & $6.0(6.0-7.0)$ & $6.0(6.0-6.0)$ & $6.0(6.0-6.0)$ \\
\hline CCI $(n=69)$, median (25th-75th percentile) & $1.0(1.0-2.0)$ & $2.0(1.0-2.0)$ & $1.0(1.0-2.0)$ \\
\hline No. of drugs (mean, SD) & $6.7(3.0)$ & $6.5(2.7)$ & $6.7(2.8)$ \\
\hline No. of psychotropic drugs ${ }^{\alpha}$, median (25th-75th percentile) & $3.0(1.3-3.8)$ & $3.0(2.0-4.0)$ & $3.0(2.0-4.0)$ \\
\hline Any psychotropic, $n(\%)$ & $34(94 \%)$ & $31(94 \%)$ & $65(94 \%)$ \\
\hline No. of sedatives ${ }^{\S}$, median (25th-75th percentile) & $0.0(0.0-0.0)$ & $0.0(0.0-0.0)$ & $0.0(0.0-0.0)$ \\
\hline Any sedatives, n (\%) & $3(8 \%)$ & $6(18 \%)$ & $9(13 \%)$ \\
\hline
\end{tabular}

$A D$ Alzheimer's Disease, $A D L$ Activities of Daily Living, CCI Charlson Comorbidity Index, FAST Functional Assessment Staging, FTD Frontotemporal dementia, LBD Lewy Body dementia, MMSE Mini Mental State Examiner, NPI-NH Neuropsychiatric inventory - nursing home version, PD Parkinson's dementia, VD Vascular dementia

Note: Medians and the 25th and 75th percentiles are presented for non-normal data. Differences at baseline were evaluated using the Student's t-test for parametric data and the Mann-Whitney $U$ test for non-parametric data (marked in italics). The Chi-square probability distribution was used to analyse categorical data

*These patients were still included as their scores on the Mini Mental State Examination and the Functional Assessment Staging suggested moderate and severe dementia. In addition, clinically trained researchers concluded that they with high probability suffered from dementia according to the DSM-5 criteria

${ }^{\circ}$ Psychotropic drugs include all drugs coded as N in the ATC system

${ }^{s}$ Sedatives include all N05C drugs, including z-hypnotics

in nursing home populations [48, 49] and homedwelling people with dementia [79]. However, other RCTs have shown beneficial effects of bright light on actigraphically assessed sleep parameters $[45,80,81]$. In a recent systematic review, we addressed several factors that may mediate the effects of BLT [51]. Although we endeavoured to reduce potential confounders in the present study, some issues related to the population, exposure, and assessment tools need to be taken into consideration. Firstly, the difference in outcomes depended

Table 2 The light levels in the intervention group and the control group

\begin{tabular}{|c|c|c|c|c|c|c|}
\hline & $\begin{array}{l}\text { Mean (SD; min- } \\
\text { max) vertical pho- } \\
\text { topic lux }\end{array}$ & $\begin{array}{l}\text { Mean (SD; min-max) } \\
\text { vertical melanopic } \\
\text { lux }\end{array}$ & $\begin{array}{l}\text { Mean (SD; min-max) } \\
\text { horizontal photopic } \\
\text { lux }\end{array}$ & $\begin{array}{l}\text { Mean (SD; min-max) } \\
\text { horizontal melanopic } \\
\text { lux }\end{array}$ & $\begin{array}{l}\text { Mean (SD; min } \\
\text { max) Kelvin } \\
\text { vertical }\end{array}$ & $\begin{array}{l}\text { Mean (SD; min- } \\
\text { max) Kelvin } \\
\text { horizontal }\end{array}$ \\
\hline Intervention & $1039(225 ; 722-1242)$ & $915(174 ; 676-1050)$ & $1842(528 ; 1388-2585)$ & $1680(557 ; 1270-2488)$ & $\begin{array}{l}5369(251 ; 5088- \\
5641)\end{array}$ & $\begin{array}{l}5521(275 ; 5211- \\
5879)\end{array}$ \\
\hline Control & $242(102 ; 134-368)$ & $137(90 ; 56-261)$ & $343(65 ; 259-408)$ & $178(52 ; 106-218)$ & $\begin{array}{l}3049(470 ; 2707- \\
3622)\end{array}$ & $\begin{array}{l}3048(397 ; \text {; 2707- } \\
3048)\end{array}$ \\
\hline$p$-value & .001 & .000 & .001 & .002 & .000 & .000 \\
\hline
\end{tabular}

Note: Vertical lux was measured $120 \mathrm{~cm}$ above the floor in the middle of the room in four directions that were averaged to produce the mean vertical illumination. Mean horizontal lux was calculated as the mean of measurements $80 \mathrm{~cm}$ above the floor in the middle of the room and $50 \mathrm{~cm}$ from the back wall. Mean lux values were calculated for the intervention and control group by averaging the values across clusters. Differences between groups tested with Student's t-test 
Table 3 The median time spent in the living room between 10:00 and 15:00 for each group

\begin{tabular}{|c|c|c|c|c|c|c|}
\hline & \multicolumn{2}{|l|}{ Week 8} & \multicolumn{2}{|l|}{ Week 16} & \multicolumn{2}{|l|}{ Week 24} \\
\hline & Mean (SD) & Median (25th-75th) & Mean (SD) & Median (25th-75th) & Mean (SD) & Median (25th-75th) \\
\hline Intervention & $3.2(1.8)$ & $3.3(1.8-5.0)$ & $3.4(1.8)$ & $4.0(2.0-5.0)$ & $3.7(1.6)$ & $5.0(2.0-5.0)$ \\
\hline Control & $3.1(1.3)$ & $3.0(2.0-4.0)$ & $2.9(1.6)$ & $3.0(1.5-5.0)$ & $2.9(1.7)$ & $3.0(2.0-5.0)$ \\
\hline$p$-value & .560 & & .482 & & .077 & \\
\hline
\end{tabular}

Note: Differences between groups tested with Mann-Whitney U test. Time in hours

on means of assessing sleep, with the analyses showing a significant treatment effect for the staff-rated SDI, in contrast to actigraphically assessed sleep. This is in line with the findings by Blytt et al. [58], who reported a significant discrepancy between actigraphically measured sleep and proxy-rated sleep in nursing home patients. In a recent publication, we found a satisfactory correspondence between the SDI and actigraphy data at baseline, in the same study population as the present study [56]. Still, actigraphy and the SDI are two very different measures of sleep, and it is possible that actigraphy was not responsive to change to the same degree as the SDI. Actigraphy is, at its core, a measure of activity, while the SDI comprises clinical assessments of sleep made by nursing home staff. Immobility during wakefulness may be miscoded as sleep by the actigraphs, and thus subtle changes in sleep and wakefulness may not be detected. Actigraphy has been shown to have a high sensitivity (ability to detect sleep) of $87-99 \%$, albeit a low specificity (ability to detect wakefulness) of $28-67 \%$ compared to polysomnography, with lower specificity occurring when sleep efficiency is reduced [82]. In older adults with insomnia, Sivertsen et al. [83] found a specificity of
$36 \%$. A potentially low specificity, i.e., poor wake detection, could have impacted the outcomes of this study. Thus, actigraphy may not have been the optimal tool to detect wakefulness in this old, multimorbid and frail population. Hence, the field needs better and more accurate, yet feasible, objective sleep recordings in dementia. One promising tool in that regard is sleep radars, which are completely non-invasive and can collect data about whole body movement, including respiration [84]. However, sleep radars have not been validated for use in nursing homes or in people with dementia. The fact that the SDI-score correlated with medication use (total number and number of psychotropic drugs), may suggest that it was clinically relevant and identified clinically significant sleep symptoms in this population.

While using a fixed rest interval for the actigraphy data was considered the best solution in the present study, this comes with important caveats. Nursing home patients may spend a substantial amount of time in bed [58], and thus the main sleep episode may take place partially outside the chosen interval from 22:00 to 06:00. Importantly, shifting the timing of the main sleep episode may significantly impact the results, even though

Table 4 Showing the results of the linear mixed model analyses

\begin{tabular}{|c|c|c|c|c|c|c|c|c|c|c|c|c|c|c|}
\hline \multirow[t]{2}{*}{ Variables } & \multirow[t]{2}{*}{$n$} & \multirow{2}{*}{$\begin{array}{l}\text { Nmb } \\
\text { obs }\end{array}$} & \multicolumn{4}{|c|}{ Baseline to week 8} & \multicolumn{4}{|c|}{ Baseline to week 16} & \multicolumn{4}{|c|}{ Baseline to week 24} \\
\hline & & & $\begin{array}{l}\text { Regression } \\
\text { coefficient }\end{array}$ & Std.error & $P$ & $\mathrm{Cl}$ & $\begin{array}{l}\text { Regression } \\
\text { coefficient }\end{array}$ & Std.error & $P$ & $\mathrm{Cl}$ & $\begin{array}{l}\text { Regression } \\
\text { coefficient }\end{array}$ & Std.error & $P$ & $\mathrm{Cl}$ \\
\hline$\overline{S E^{a}}$ & 65 & 201 & -0.32 & 3.18 & .920 & $\begin{array}{l}-6.56- \\
5.92\end{array}$ & 2.97 & 3.36 & .377 & $\begin{array}{l}-3.60- \\
9.55\end{array}$ & -3.65 & 3.26 & .264 & $\begin{array}{l}-10.04- \\
2.73\end{array}$ \\
\hline $\begin{array}{l}\text { TST } 24 \\
h^{b, c}\end{array}$ & 65 & 194 & -52.18 & 30.86 & .093 & $\begin{array}{l}-112.66- \\
8.03\end{array}$ & -36.11 & 33.95 & .290 & $\begin{array}{l}-102.64- \\
30.43\end{array}$ & -12.46 & 31.41 & .692 & $\begin{array}{l}-74.03- \\
49.10\end{array}$ \\
\hline TST day ${ }^{c}$ & 65 & 201 & 6.65 & 14.03 & .636 & $\begin{array}{l}-20.84- \\
34.14\end{array}$ & 24.83 & 14.79 & .096 & $\begin{array}{l}-4.16- \\
53.81\end{array}$ & 21.44 & 14.35 & .138 & $\begin{array}{l}-6.69- \\
49.57\end{array}$ \\
\hline WASO $^{d}$ & 65 & 201 & 14.42 & 10.43 & .169 & $\begin{array}{l}-6.03- \\
34.86\end{array}$ & 2.59 & 10.98 & .814 & $\begin{array}{l}-18.92- \\
24.11\end{array}$ & 20.92 & 10.68 & .052 & $\begin{array}{l}0.01- \\
41.85\end{array}$ \\
\hline SDI $\operatorname{trans}^{\mathrm{e}}$ & 66 & 213 & -0.04 & .02 & .094 & $\begin{array}{l}-0.09- \\
0.01\end{array}$ & -0.06 & .03 & .020 & $\begin{array}{l}-0.11-- \\
0.01\end{array}$ & -0.05 & 0.02 & .028 & $\begin{array}{l}-0.10-- \\
0.01\end{array}$ \\
\hline
\end{tabular}

Note: The R package Ime4 assumes an unstructured variance-covariance structure

Cl confidence interval, Nmb obs Number of observations, $P$ p-value, SDI Sleep Disorder Inventory, SE (variable) sleep efficiency, std.error standard error, trans transformed, TST total sleep time, WASO wake after sleep onset

Note: The regression coefficients reflect the change from baseline in the intervention group compared to the control group

${ }^{a}$ Eye disease included as covariate

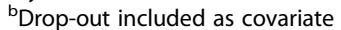

'Total Functional Assessment Staging score in the relevant week included as covariate

${ }^{\mathrm{d}}$ Age included as covariate

${ }^{\mathrm{e}}$ Average number of psychotropic medications included as covariate 
Table 5 Observed means and standard deviations for the groups at each time point, with medians and 25th and 76th percentiles reported for non-normal data

\begin{tabular}{|c|c|c|c|c|c|c|c|c|c|}
\hline & & \multicolumn{4}{|c|}{ Intervention group } & \multicolumn{4}{|c|}{ Control group } \\
\hline & & Baseline & Week 8 & Week 16 & Week 24 & Baseline & Week 8 & Week 16 & Week 24 \\
\hline \multirow[t]{2}{*}{$\overline{S E}$} & Mean (SD) & $75.0(18.6)$ & $74.8(14.5)$ & $76.5(15.7)$ & $71.8(18.8)$ & $72.4(16.3)$ & $70.3(15.4)$ & $69.2(13.4)$ & $71.7(15.2)$ \\
\hline & Median (25th-75th) & $\begin{array}{l}80.2(67.0- \\
90.8)\end{array}$ & $\begin{array}{l}76.9(67.7- \\
88.5)\end{array}$ & $\begin{array}{l}80.0(70.7- \\
89.1)\end{array}$ & $\begin{array}{l}76.6(58.1- \\
87.0)\end{array}$ & $\begin{array}{l}79.0(59.0- \\
87.5)\end{array}$ & $\begin{array}{l}75.7(55.3- \\
81.3)\end{array}$ & $\begin{array}{l}70.2(60.7- \\
79.4)\end{array}$ & $\begin{array}{l}72.4(60.5- \\
84.2)\end{array}$ \\
\hline \multirow{2}{*}{$\begin{array}{l}\text { TST } \\
\text { night }\end{array}$} & Mean (SD) & $359.9(89.3)$ & $358.8(69.6)$ & $367.0(75.3)$ & $344.5(90.0)$ & $347.6(78.3)$ & $339.2(75.2)$ & $332.0(64.3)$ & $344.1(73.2)$ \\
\hline & Median (25th-75th) & $\begin{array}{l}385.1 \\
(321.4- \\
432.1)\end{array}$ & $\begin{array}{l}368.3 \\
(324.9- \\
425.0)\end{array}$ & $\begin{array}{l}383.4 \\
(240.0- \\
427.7)\end{array}$ & $\begin{array}{l}367.6 \\
(278.6- \\
415.2)\end{array}$ & $\begin{array}{l}379.1 \\
(283.1- \\
419.9)\end{array}$ & $\begin{array}{l}364.4 \\
(265.6- \\
394.7)\end{array}$ & $\begin{array}{l}336.9 \\
(291.3- \\
381.3)\end{array}$ & $\begin{array}{l}347.4 \\
(290.6- \\
404.3)\end{array}$ \\
\hline $\begin{array}{l}\text { TST } 24 \\
\text { h }\end{array}$ & Mean (SD) & $623.3(162.0)$ & $623.3(162.0)$ & $597.7(137.3)$ & $626.2(179.7)$ & $669.2(182.7)$ & $655.5(157.1)$ & $646.2(152.9)$ & $664.6(186.4)$ \\
\hline $\begin{array}{l}\text { TST } \\
\text { day }\end{array}$ & Mean (SD) & $125.4(70.3)$ & $119.9(73.0)$ & $141.2(100.2)$ & $137.1(82.3)$ & $176.2(93.1)$ & $150.0(91.5)$ & $159.0(90.9)$ & $154.5(88.6)$ \\
\hline WASO & Mean (SD) & $58.8(32.4)$ & $65.7(36.4)$ & $56.3(23.7)$ & $75.3(48.7)$ & $76.3(50.0)$ & $73.4(43.5)$ & $73.6(33.7)$ & $71.7(39.1)$ \\
\hline \multirow[t]{3}{*}{ SDI } & Mean (SD) & $10.3(14.9)$ & $8.0(8.8)$ & $7.7(12.3)$ & $6.9(10.7)$ & $10.0(12.8)$ & $19.2(21.3)$ & $10.8(10.5)$ & $9.4(10.3)$ \\
\hline & Median (25th-75th) & $\begin{array}{l}3.0(0.0- \\
13.0)\end{array}$ & $\begin{array}{l}5.5(1.5- \\
12.0)\end{array}$ & $\begin{array}{l}2.0(0.0- \\
12.0)\end{array}$ & $\begin{array}{l}2.0(0.0- \\
10.0)\end{array}$ & $\begin{array}{l}3.0(0.0- \\
18.0)\end{array}$ & $\begin{array}{l}12.0(2.0- \\
32.0)\end{array}$ & $\begin{array}{l}5.5(2.0- \\
21.0)\end{array}$ & $\begin{array}{l}5.0(3.0- \\
14.0)\end{array}$ \\
\hline & $\begin{array}{l}\text { Proportion with sleep } \\
\text { problems, } \mathrm{n}(\%)^{*}\end{array}$ & $12(40.0)$ & $11(47.8)$ & $8(40.0)$ & $8(33.3)$ & $14(45.2)$ & $12(44.4)$ & $14(60.9)$ & $12(54.5)$ \\
\hline
\end{tabular}

*Sleep problems defined as sleep efficiency $<75 \%$

SE sleep efficiency, SD standard deviation, SDI Sleep Disorder Inventory, TST total sleep time, WASO wake after sleep onset

the person's sleep is otherwise identical. For example, if a patient slept from 22:30-06:00 at baseline and then shifted the sleep episode to 23:30-07:00 at follow-up, this would according to the actigraph be interpreted as a deterioration of sleep. The SDI is more flexible in this regard.

Further, the somatic and mental health status of the patients may have affected sleep and/or mobility to the extent that it reduced discernible changes in the actigraphy-measured sleep. In addition, there was a high use of psychotropic drugs which combined to a high sedative load [85]. This may have reduced mobility and consequently affected the actigraphy data to a greater extent than the SDI data. In addition, somatic conditions including pain are known to reduce movement in this population [86].

The study participants were old (mean 84 years) and had severe dementia. As neurodegeneration increasingly affects sleep regulatory systems and eye physiology [5, $17,29,30]$, the lack of effects on actigraphy outcomes may indicate that the patients had limited benefit from BLT. Hence, it is possible that people with milder dementia would have benefitted more from BLT. This should be addressed in future studies.

Another important aspect to consider is the presence of eye disease among the participants. At baseline, those with eye disease had worse sleep than those with no eye disease. This variable was, however, only included in the

Table 6 Showing the correlation coefficients ( $p$-values) between the sleep variables and scores on other variables at baseline

\begin{tabular}{lllllll}
\hline & Age & No. drugs & No. psychotropic & No. sedatives & MMSE & FAST \\
\hline WASO & -.18 & -.03 & .04 & -.06 & -.03 & .01 \\
TST day & -.01 & -.01 & .04 & -.18 & .04 & -.03 \\
TST 24h & .02 & .05 & .09 & -.15 & .07 & -.05 \\
SE & .01 & .01 & .02 & .01 & .09 & -.12 \\
SDI & -.12 & $.30^{*}$ & $.35^{* *}$ & .19 & -.03 & -.11 \\
\hline
\end{tabular}

Note: The significance level was set to $p<.05$. Italics indicate non-normal data. Any pair with non-normal data was analysed using Spearman's rho (italics). Normal data was analysed using Pearson correlation

CCI Charlson Comorbidity Index, FAST The Functional Assessment Staging, MMSE Mini Mental State Examination, TST total sleep time, SDI Sleep Disorder Inventory, SE sleep efficiency, WASO wake after sleep onset

*Significant at $p<.05$

**Significant at $p<.01$ 
final regression model of SE, as it affected the model fit only for this outcome, indicating that the presence of eye disease did not significantly influence the outcomes. Still, the difference at baseline may suggest that the baseline lighting was more problematic to those with impaired vision; however, there were too few individuals to investigate whether this group in particular benefitted from BLT.

Environmental factors may have confounded intervention effects. One of the first studies using ceilingmounted light found that morning and all-day treatment $(6500 \mathrm{~K}$ and 500-600 lx) were associated with the greatest amount of sleep, compared to evening treatment and standard light [87]. However, when controlling for study location, they found opposing effects of BLT on daytime sleepiness in the two included nursing home units, suggesting that other factors were at play. In the nursing home context, the day-to-day routines have a fundamental impact on the patients. For example, patients are often put to bed quite early and helped out of bed quite late in the morning. Consequently, some patients may end up spending more than $12 \mathrm{~h}$ in bed [58]. This may cause low sleep efficiency and increase the risk of nocturnal wakefulness. Also, other factors such as noise and light exposure at night are known to contribute to disrupted sleep in nursing home patients [88]. Together, influences from such environmental factors might have attenuated any positive effects of BLT in the present study.

Because BLT only affected subjectively measured sleep, it should be considered if this was caused by placebo-byproxy [89] or similar phenomena. Light is inherently visible, and it was thus impossible to create a placebo condition that was identical to the intervention. Consequently, it is possible that the nurses in the control group realised that the new light bulbs in fact delivered standard light levels and that placebo-by-proxy effects only operated in the intervention group. However, if such effects were present, they should have appeared already in week 8 . Thus, it is likely that the discrepancy in results between the two approaches of measuring sleep relates to the inherent differences between these measures and not to placebo-by-proxy effects.

\section{Limitations}

The present study had some important limitations. The results show that blinding was successful only for a minority of the staff. However, success of blinding was assessed after revealing the design to the staff, which has been argued to yield questionable/invalid data [54]. In addition, the response rate among the nurses was low, and it is possible that those who did answer the blinding questions were more interested in the research than the nurses who did not respond.
The exact amount of light received by each participant was not measured. Although equipment for the purpose of continuously measuring light exposure at eye level (e.g., [90]) has been developed (attaching a light meter to the head), this has limited feasibility in a dementia sample. Exposure estimations based on standardised light meter recordings and time spent in the common room as reported by the nurses were thus considered the best option, although it would not correlate perfectly with real exposure.

There was some variation in light levels across units, where one control unit had higher mean light levels (261 melanopic lux) compared to the other control units (56143 melanopic lux), and one intervention unit achieved lower-than-intended light levels (675 melanopic lux compared to 900-1050) (Table S1). Still, there was a minimum of a 400 melanopic lux difference between the control unit with the highest light levels, and the intervention unit with the lowest light levels, and controlling for light levels did not impact the results.

In the present study, we implemented the intervention only during the day in the common rooms. Hence, bedroom lighting was not a part of the intervention. Light exposure during the night (e.g., in bedrooms) may significantly disrupt sleep and ensuring darkness or bluedepleted light in the patients' bedrooms at night could perhaps have caused a more robust effect.

The timing of the study (September-April) was chosen to include the dark season. Even though indoor light levels in nursing homes are low even in sunny weather conditions [36], there is a theoretical possibility that any beneficial effects of daylight availability during the summer and early autumn lingered during the baseline data collection. Similarly, the last data collection at week 24 was partially performed after the spring equinox, which might represent a confounding variable.

Due to a higher attrition rate than anticipated and some missing data due to non-compliance to actigraphy (Fig. 3), we ended up with a lower number of participants than recommended by our power analysis. This needs to be taken into consideration when interpreting the results.

\section{Strengths}

To avoid any potential carry-over effects of BLT, we used a parallel group design. The BLT was delivered for a long period of time to evaluate both short-term and long-term effects. Light levels were measured in a standardised manner and reported in the appropriate light metric accounting for the sensitivity of the circadian system (melanopic lux). This study demonstrated that it is feasible to install ambient light systems in nursing homes. Further, including dementia units from eight different nursing homes and using lenient inclusion criteria 
provided a representative study population and high ecological validity.

\section{Conclusion}

The present findings indicate that BLT improved proxyrated sleep among nursing home patients with dementia after 16 and 24 weeks of treatment compared to a control group. The lack of improvement in proxy-rated sleep at week 8 may suggest that several weeks of exposure is necessary to detect beneficial effects of BLT. There was no evidence for an effect of BLT on actigraphically measured sleep. Despite the results being mixed, there is reason to assume that BLT may be beneficial for people with severe dementia.

\section{Abbreviations}

ADL: Activities of Daily Living; BLT: Bright light treatment; CCl: Charlson Comorbidity Index; CCT: Correlated colour temperature; FAST: Functional Assessment Staging; ipRGCs: Intrinsically photosensitive retinal ganglion cells; K: Kelvin; LED: Light emitting diode; MMSE: Mini Mental State Examination; RCT: Randomised controlled trial; SCN: Suprachiasmatic nucleus; SDI: Sleep Disorder Inventory; SE: Sleep efficiency; TST: Total sleep time; WASO: Wakeafter-sleep-onset

\section{Supplementary Information}

The online version contains supplementary material available at https://doi. org/10.1186/s12877-021-02236-4.

Additional file 1: Supplementary Table S1. Table showing the light levels in each cluster of the intervention group and the control group

\section{Acknowledgements \\ The authors are grateful to the people who participated in the study and for the support and effort from nursing home staff at the participating units. Further, we are grateful for the help offered by research assistants Marianne Hvattum Løken and Kristin Stotesbury during the data collection. \\ Some of the results reported in this article were presented at the Virtual Congress of the European Sleep Research Society 2020 (doi: https://doi.org/ 10.1111/jsr.13181).}

\section{Authors' contributions}

$E F, S P, I H N, E T, G J H, E K$, and BB were involved in the conception and design of the work. GJH, EK, and ET were involved in the acquisition of the data. EK, $E F, S P, E T, I H N$, and GJH were involved in the analysis of the data, and EK, EF, $S P, E T, I H N, G J H$, and BB were involved in the interpretation of the data and the drafting and revision of the work. All authors have read and approved the manuscript.

\section{Funding}

The Research Council of Norway and City Department of Health and Care, City of Bergen, funded the PhD grant for Gunnhild J. Hjetland (Sponsor's Protocol Code 259987/H40). Hjetland has also received funding from Thordis and Johannes Gahrs Fund for Promoting Gerontopsychiatric Research. The DEM.LIGHT trial received funding for light equipment from the Rebekka Ege Hegermanns Grant and the GC Rieber Foundations. The funding sources had no involvement in the study design, the collection, analysis, or interpretation of data, or in writing the manuscript.

\section{Availability of data and materials}

The dataset analysed during the current study is available from the corresponding author on reasonable request.

\section{Declarations}

Ethics approval and consent to participate

The study was approved by the Regional Committee for Medical and Health Research Ethics, Health Region South East (project no. 2016/2246).

The researchers endeavoured to inform all participants about the study in an adapted way. Patients who potentially had the capacity to provide informed consent were identified through conversations with the physician at each nursing home. Most patients were not able to provide consent (either orally or in writing). In these cases, the patients' legal guardians were contacted directly. After being approached by a phone call, the legal guardians received a letter by postal mail containing all relevant information about the aims, procedures, and ethical approval of the trial, after which they gave both written and oral presumed informed consent on behalf of the patient. When contemplating presumed consent, the patient's guardian was instructed to consider what the patient would have wished for in the specific situation, not what they themselves believed was most pertinent. Across the study period, the researchers were sensitive to any expressions of discomfort or protests from the participants and considered this as withdrawal of consent. The extraction from medical records was approved by the ethics committee and Bergen Municipality, and participants were informed and consented to this data collection. The researcher extracting data from the medical records was a clinical psychologist employed by Bergen Municipality who signed an agreement of confidentiality and nondisclosure form prior to extracting data.

\section{Consent for publication}

Not applicable.

\section{Competing interests}

The authors declare that they have no competing interests.

\section{Author details}

${ }^{1}$ Department of Clinical Psychology, Faculty of Psychology, University of Bergen, Bergen, Norway. ${ }^{2}$ City Department of Health and Care, City of Bergen, Norway. ${ }^{3}$ Norwegian Institute of Public Health, Bergen, Norway. ${ }^{4}$ Norwegian Competence Center for Sleep Disorders, Haukeland University Hospital, Bergen, Norway. ${ }^{5}$ Department of Psychosocial Science, Faculty of Psychology, University of Bergen, Bergen, Norway. ${ }^{6}$ Department of Behavioural Medicine, Faculty of Medicine, University of Oslo, Oslo, Norway. ${ }^{7}$ Department of Global Public Health and Primary Care, Faculty of Medicine, University of Bergen, Bergen, Norway.

Received: 1 July 2020 Accepted: 20 April 2021

Published online: 17 May 2021

\section{References}

1. American Psychiatric Association. Neurocognitive disorders. Diagnostic and Statistical Manual of Mental Disorders. 5th ed. Washington DC; 2013.

2. Wimo A, Guerchet M, Ali G-C, Wu Y-T, Prina AM, Winblad B, et al. The worldwide costs of dementia 2015 and comparisons with 2010. Alzheimers Dement. 2017;13(1):1-7. https://doi.org/10.1016/j.jalz.2016.07.150.

3. World Health Organization. Dementia [Internet]. 2019. Available from: https://www.who.int/news-room/fact-sheets/detail/dementia

4. Webster L, Costafreda Gonzalez S, Stringer A, Lineham A, Budgett J, Kyle S, et al. Measuring the prevalence of sleep disturbances in people with dementia living in care homes: a systematic review and meta-analysis. Sleep. 2019;43:zsz251.

5. Wulff K, Gatti S, Wettstein JG, Foster RG. Sleep and circadian rhythm disruption in psychiatric and neurodegenerative disease. Nat Rev Neurosci. 2010;11(8):589-99. https://doi.org/10.1038/nrn2868.

6. Ornstein K, Gaugler JE. The problem with "problem behaviors": a systematic review of the association between individual patient behavioral and psychological symptoms and caregiver depression and burden within the dementia patient-caregiver dyad. Int Psychogeriatr. 2012;24(10):1536-52. https://doi.org/10.1017/S1041610212000737.

7. Brassington GS, King AC, Bliwise DL. Sleep problems as a risk factor for falls in a sample of community-dwelling adults aged 64-99 years. J Am Geriatr Soc. 2000;48(10):1234-40. https://doi.org/10.1111/j.1532-5415.2000.tb02596.x.

8. Stone KL, Ancoli-lsrael S, Blackwell T, Ensrud KE, Cauley JA, Redline S, et al. Actigraphy-measured sleep characteristics and risk of falls in older women. 
Arch Intern Med Am Med Assoc. 2008;168(16):1768-75. https://doi.org/10.1 001/archinte.168.16.1768.

9. Anderson KN, Catt M, Collerton J, Davies K, von Zglinicki T, Kirkwood TB, et al. Assessment of sleep and circadian rhythm disorders in the very old: the Newcastle 85+ cohort study. Age Ageing. 2014;43(1):57-63. https://doi. org/10.1093/ageing/aft153.

10. Arbus C, Gardette V, Cantet CE, Andrieu S, Nourhashémi F, Schmitt L, et al. Incidence and predictive factors of depressive symptoms in Alzheimer's disease: the REAL.FR study. J Nutr Health Aging. 2011;15(8):609-17. https:// doi.org/10.1007/s12603-011-0061-1.

11. Guarnieri B, Adorni F, Musicco M, Appollonio I, Bonanni E, Caffarra P, et al. Prevalence of sleep disturbances in mild cognitive impairment and dementing disorders: a multicenter Italian clinical cross-sectional study on 431 patients. Dement Geriatr Cogn Disord. 2012;33(1):50-8. https://doi.org/1 $0.1159 / 000335363$.

12. Tractenberg RE, Singer CM, Cummings $J \mathrm{~L}$, Thal $L$ J. The sleep disorders inventory: an instrument for studies of sleep disturbance in persons with Alzheimer's disease. J Sleep Res. 2003;12(4):331-7. https://doi.org/10.1046/j. 0962-1105.2003.00374.X.

13. Yaffe K, Falvey CM, Hoang T. Connections between sleep and cognition in older adults. Lancet Neurol. 2014;13(10):1017-28. https://doi.org/10.1016/S14 74-4422(14)70172-3.

14. Deschenes $\mathrm{CL}$, McCurry SM. Current treatments for sleep disturbances in individuals with dementia. Curr Psychiatry Rep. 2009;11(1):20-6. https://doi. org/10.1007/s11920-009-0004-2

15. Sterke CS, van Beeck EF, van der Velde N, Ziere G, Petrovic M, Looman CW, et al. New insights: dose-response relationship between psychotropic drugs and falls: a study in nursing home residents with dementia. J Clin Pharmacol. 2012;52(6):947-55. https://doi.org/10.1177/0091270011405665.

16. McCleery J, Cohen DA, Sharpley AL. Pharmacotherapies for sleep disturbances in Alzheimer's disease. BJPsych Adv. 2015;21(4):218-8. https:// doi.org/10.1192/apt.21.4.218.

17. Pat-Horenczyk R, Klauber MR, Shochat T, Ancoli-Israel S. Hourly profiles of sleep and wakefulness in severely versus mild-moderately demented nursing home patients. Aging Clin Exp Res. 1998;10(4):308-15. https://doi. org/10.1007/BF03339793.

18. Wennberg AM, Wu MN, Rosenberg PB, Spira AP. Sleep disturbance, cognitive decline, and dementia: a review. Semin Neurol. 2017;37:395-406.

19. Neikrug $A B$, Ancoli-Israel $S$. Sleep disturbances in nursing homes. J Nutr Health Aging. 2010;14(3):207-11. https://doi.org/10.1007/s12603-010-0051-8.

20. Peter-Derex L, Yammine P, Bastuji H, Croisile B. Sleep and Alzheimer's disease. Sleep Med Rev. 2015;19:29-38. https://doi.org/10.1016/j.smrv.2014. 03.007.

21. Figueiro MG, Hamner R, Higgins P, Hornick T, Rea MS. Field measurements of light exposures and circadian disruption in two populations of older adults. J Alzheimers Dis. 2012;31(4):711-5. https://doi.org/10.3233/JAD-2 012-120484

22. Shochat T, Martin J, Marler M, Ancoli-Israel S. Illumination levels in nursing home patients: effects on sleep and activity rhythms. J Sleep Res. 2000;9(4): 373-9. https://doi.org/10.1046/j.1365-2869.2000.00221.x.

23. Czeisler CA, Buxton OM. Human circadian timing system and sleep-wake regulation. In: Kryger M, Roth T, Dement WC, editors. Principles and Practice of Sleep Medicine. 5th ed. United States: Elsevier Inc; 2010. p. 402- 419.e5.

24. Berson DM, Dunn FA, Takao M. Phototransduction by retinal ganglion cells that set the circadian clock. Science. 2002;295(5557):1070-3. https://doi. org/10.1126/science.1067262.

25. Dacey DM, Liao H-W, Peterson BB, Robinson FR, Smith VC, Pokorny J, et al. Melanopsin-expressing ganglion cells in primate retina signal colour and irradiance and project to the LGN. Nature. 2005;433(7027):749-54. https:// doi.org/10.1038/nature03387.

26. Cajochen C, Munch M, Kobialka S, Krauchi K, Steiner R, Oelhafen P, et al. High sensitivity of human melatonin, alertness, thermoregulation, and heart rate to short wavelength light. J Clin Endocrinol Metab. 2005;90(3):1311-6. https://doi.org/10.1210/jc.2004-0957

27. Brainard GC, Hanifin JP, Warfield B, Stone MK, James ME, Ayers M, et al. Short-wavelength enrichment of polychromatic light enhances human melatonin suppression potency. J Pineal Res. 2015;58(3):352-61. https://doi. org/10.1111/jpi.12221.

28. Peyvandi S, Hernández-Andrés J, Olmo FJ, Nieves JL, Romero J. Colorimetric analysis of outdoor illumination across varieties of atmospheric conditions. JOSA A. 2016;33(6):1049-59. https://doi.org/10.1364/JOSAA.33.001049.
29. Duffy JF, Zitting K-M, Chinoy ED. Aging and circadian rhythms. Sleep Med Clin. 2015;10(4):423-34. https://doi.org/10.1016/j.jsmc.2015.08.002.

30. Turner PL, Mainster MA. Circadian photoreception: ageing and the eye's important role in systemic health. Br J Ophthalmol. 2008;92(11):1439-44. https://doi.org/10.1136/bjo.2008.141747.

31. Najjar RP, Chiquet C, Teikari P, Cornut P-L, Claustrat B, Denis P, et al. Aging of non-visual spectral sensitivity to light in humans: compensatory mechanisms? PLoS One. 2014;9(1):e85837. https://doi.org/10.1371/journal. pone.0085837.

32. Kessel L, Siganos G, Jørgensen T, Larsen M. Sleep disturbances are related to decreased transmission of blue light to the retina caused by lens yellowing. Sleep. 2011;34(9):1215-9. https://doi.org/10.5665/SLEEP.1242.

33. La Morgia C, Ross-Cisneros FN, Sadun AA, Carelli V. Retinal ganglion cells and circadian rhythms in Alzheimer's disease, Parkinson's disease, and beyond. Front Neurol. 2017;8:162. https://doi.org/10.3389/fneur.2017.00162.

34. Ancoli-Israel S, Klauber MR, Jones DW, Kripke DF, Martin J, Mason W, et al. Variations in circadian rhythms of activity, sleep, and light exposure related to dementia in nursing-home patients. Sleep. 1997;20:18-23.

35. De Lepeleire J, Bouwen A, De Coninck L, Buntinx F. Insufficient lighting in nursing homes. J Am Med Dir Assoc. 2007;8(5):314-7. https://doi.org/10.101 6/j.jamda.2007.01.003.

36. Konis K. Field evaluation of the circadian stimulus potential of daylit and non-daylit spaces in dementia care facilities. Build Environ. 2018;135:112-23. https://doi.org/10.1016/j.buildenv.2018.03.007.

37. Sinoo MM, van Hoof J, Kort HS. Light conditions for older adults in the nursing home: assessment of environmental illuminances and colour temperature. Build Environ. 2011;46(10):1917-27. https://doi.org/10.1016/j. buildenv.2011.03.013.

38. Kolberg E, Pallesen S, Hjetland GJ, Nordhus IH, Thun E, Flo-Groeneboom E. Insufficient melanopic equivalent daylight illuminance in nursing home dementia units across seasons and gaze directions. Light Res Technol. 2021. 1477153521994539.

39. Li DHW, Lau CCS, Lam JC. Predicting daylight illuminance on inclined surfaces using sky luminance data. Energy. 2005;30(9):1649-65. https://doi. org/10.1016/j.energy.2004.04.038.

40. Norton TT, Siegwart JT Jr. Light levels, refractive development, and myopiaa speculative review. Exp Eye Res. 2013;114:48-57. https://doi.org/10.1016/j. exer.2013.05.004

41. Ancoli-Israel S, Gehrman P, Martin JL, Shochat T, Marler M, Corey-Bloom J, et al. Increased light exposure consolidates sleep and strengthens circadian rhythms in severe Alzheimer's disease patients. Behav Sleep Med. 2003;1(1): 22-36. https://doi.org/10.1207/S15402010BSM0101_4.

42. Fetveit A, Skjerve A, Bjorvatn B. Bright light treatment improves sleep in institutionalised elderly—an open trial. Int J Geriatri Psych. 2003;18(6):520-6. https://doi.org/10.1002/gps.852.

43. Lyketsos CG, Veiel LL, Baker A, Steele C. A randomized, controlled trial of bright light therapy for agitated behaviors in dementia patients residing in long-term care. Int J Geriatr Psychiatry. 1999;14(7):520-5. https://doi.org/10.1 002/(SICI) 1099-1166(199907)14:7<520::AID-GPS983>3.0.CO;2-M.

44. Mishima K, Okawa M, Hishikawa Y, Hozumi S, Hori H, Takahashi K. Morning bright light therapy for sleep and behavior disorders in elderly patients with dementia. Acta Psychiatr Scand. 1994;89(1):1-7. https://doi.org/10.1111/j.1 600-0447.1994.tb01477.x.

45. Mishima K, Hishikawa Y, Okawa M. Randomized, dim light controlled, crossover test of morning bright light therapy for rest-activity rhythm disorders in patients with vascular dementia and dementia of Alzheimer's type. Chronobiol Int. 1998;15(6):647-54. https://doi.org/10.3109/07420529808993200.

46. Satlin A, Volicer L, Ross V, Herz L, Campbell S. Bright light treatment of behavioral and sleep disturbances in patients with Alzheimer's disease. Am J Psychiatry. 1992;149:1028-32.

47. Yamadera H, Ito T, Suzuki H, Asayama K, Ito R, Endo S. Effects of bright light on cognitive and sleep-wake (circadian) rhythm disturbances in Alzheimertype dementia. Psychiatry Clin Neurosci. 2000;54(3):352-3. https://doi.org/1 0.1046/j.1440-1819.2000.00711.x.

48. Ancoli-Israel S, Martin JL, Kripke DF, Marler M, Klauber MR. Effect of light treatment on sleep and circadian rhythms in demented nursing home patients. J Am Geriatr Soc. 2002;50(2):282-9. https://doi.org/10.1046/j.15325415.2002.50060x

49. Burns A, Allen H, Tomenson B, Duignan D, Byrne J. Bright light therapy for agitation in dementia: a randomized controlled trial. Int Psychogeriatr. 2009; 21(4):711-21. https://doi.org/10.1017/S1041610209008886. 
50. Skjerve A, Bjorvatn B, Holsten F. Light therapy for behavioural and psychological symptoms of dementia. Int J Geriatri Psych. 2004;19(6):516-22. https://doi.org/10.1002/gps.1087.

51. Hjetland GJ, Pallesen S, Thun E, Kolberg E, Nordhus IH, Flo E. Light interventions and sleep, circadian, behavioral, and psychological disturbances in dementia: a systematic review of methods and outcomes. Sleep Med Rev. 2020:101310.

52. Chiu H-L, Chan P-T, Chu H, Hsiao S-TS, Liu D, Lin C-H, et al. Effectiveness of light therapy in cognitively impaired persons: a metaanalysis of randomized controlled trials. J Am Geriatr Soc. 2017;65(10):2227-34. https://doi.org/1 $0.1111 /$ jgs. 14990 .

53. van Maanen A, Meijer AM, van der Heijden KB, Oort FJ. The effects of light therapy on sleep problems: a systematic review and meta-analysis. Sleep Med Rev. 2016;29:52-62. https://doi.org/10.1016/j.smrv.2015.08.009.

54. Schulz KF, Altman DG, Moher D. the CONSORT Group. CONSORT 2010 Statement: updated guidelines for reporting parallel group randomised trials. BMC Med. 2010;8:18

55. Lucas RJ, Peirson SN, Berson DM, Brown TM, Cooper HM, Czeisler CA, et al. Measuring and using light in the melanopsin age. Trends Neurosci. 2014; 37(1):1-9. https://doi.org/10.1016/j.tins.2013.10.004.

56. Hjetland GJ, Nordhus IH, Pallesen S, Cummings J, Tractenberg RE, Thun E, et al. An Actigraphy-based validation study of the sleep disorder inventory in the nursing home. Front Psychiatr. 2020;11:173. https://doi.org/10.3389/ fpsyt.2020.00173.

57. Ancoli-Israel S, Cole R, Alessi C, Chambers M, Moorcroft W, Pollak CP. The role of actigraphy in the study of sleep and circadian rhythms. Sleep. 2003 26(3):342-92. https://doi.org/10.1093/sleep/26.3.342.

58. Blytt KM, Bjorvatn B, Husebo B, Flo E. Clinically significant discrepancies between sleep problems assessed by standard clinical tools and actigraphy. BMC Geriatr. 2017;17(1):253. https://doi.org/10.1186/s12877-017-0653-7.

59. Fetveit A, Bjorvatn B. Sleep disturbances among nursing home residents. Int J Geriatri Psych. 2002;17(7):604-9. https://doi.org/10.1002/gps.639.

60. Martin JL, Webber AP, Alam T, Harker JO, Josephson KR, Alessi CA. Daytime sleeping, sleep disturbance, and circadian rhythms in the nursing home. Am J Geriatr Psychiatry. 2006;14(2):121-9. https://doi.org/10.1097/01.JGP. 0000192483.35555.a3.

61. Camargos EF, Louzada FM, Nóbrega OT. Wrist actigraphy for measuring sleep in intervention studies with Alzheimer's disease patients: application usefulness, and challenges. Sleep Med Rev. 2013;17(6):475-88. https://doi. org/10.1016/j.smrv.2013.01.006

62. Brown DT, Westbury JL, Schüz B. Sleep and agitation in nursing home residents with and without dementia. Int Psychogeriatr. 2015;27(12):194555. https://doi.org/10.1017/S1041610215001568.

63. Bonanni E, Maestri M, Tognoni G, Fabbrini M, Nucciarone B, Manca ML, et al. Daytime sleepiness in mild and moderate Alzheimer's disease and its relationship with cognitive impairment. J Sleep Res. 2005;14(3):311-7. https://doi.org/10.1111/j.1365-2869.2005.00462.x.

64. Folstein MF, Folstein SE, McHugh PR. "Mini-mental state": a practical method for grading the cognitive state of patients for the clinician. J Psychiatr Res. 1975;12(3):189-98. https://doi.org/10.1016/0022-3956(75)90026-6.

65. Sclan SG, Reisberg B. Functional assessment staging (FAST) in Alzheimer's disease: reliability, validity, and ordinality. Int Psychogeriatr. 1992;4(3):55-69. https://doi.org/10.1017/S1041610292001157.

66. Charlson ME, Pompei P, Ales KL, MacKenzie CR. A new method of classifying prognostic comorbidity in longitudinal studies: development and validation. J Chronic Dis. 1987;40(5):373-83. https://doi.org/10.1016/0021-9681(87)901 71-8.

67. Lawton MP, Brody EM. Assessment of older people: self-maintaining and instrumental activities of daily living. Gerontologist. 1969;9(3 Part 1):179-86. https://doi.org/10.1093/geront/9.3_Part_1.179.

68. Selbaek $G$, Kirkevold $\varnothing$, Sommer $\mathrm{OH}$, Engedal $K$. The reliability and validity of the Norwegian version of the neuropsychiatric inventory, nursing home version (NPI-NH). Int Psychogeriatr. 2008;20(2):375-82. https://doi.org/10.101 7/S1041610207005601.

69. Cummings JL, Mega M, Gray K, Rosenberg-Thompson S, Carusi DA, Gornbein J. The neuropsychiatric inventory comprehensive assessment of psychopathology in dementia. Neurology. 1994;44(12):2308-8. https://doi. org/10.1212/WNL.44.12.2308.

70. Faul F, Erdfelder E, Buchner A, Lang A-G. Statistical power analyses using G* power 3.1: tests for correlation and regression analyses. Behav Res Methods. 2009;41(4):1149-60. https://doi.org/10.3758/BRM.41.4.1149.
71. Donner A. Some aspects of the design and analysis of cluster randomization trials. J R Stat Soc C-Appl Wiley Online Library. 1998;47:95113.

72. Franke $\mathrm{RH}$, Kaul JD. The Hawthorne experiments: first statistical interpretation. Am Sociol Rev. 1978;43(5):623-43. https://doi.org/10.2307/2 094540.

73. McCarney R, Warner J, lliffe S, Van Haselen R, Griffin M, Fisher P. The Hawthorne effect: a randomised, controlled trial. BMC Med Res Methodol. 2007;7(1):30. https://doi.org/10.1186/1471-2288-7-30.

74. Akobeng AK. Assessing the validity of clinical trials. J Pediatr Gastr Nutr. 2008:47(3):277-82. https://doi.org/10.1097/MPG.0b013e31816c749f.

75. R Core Team. R: A language and environment for statistical computing. Vienna: R Foundation for statistical Computing; 2014. Available from: https:// www.R-project.org/

76. Bates $\mathrm{D}$, Mächler $\mathrm{M}$, Bolker $\mathrm{B}$, Walker S. Fitting linear mixed-effects models using Ime4. arXiv preprint arXiv:14065823. 2014;

77. Adamis D. Statistical methods for analysing longitudinal data in delirium studies. Int Rev Psychiatry. 2009;21(1):74-85. https://doi.org/10.1080/095402 60802675346

78. Brown H, Prescott R. Applied mixed models in medicine. John Wiley \& Sons; 2014.

79. Sloane PD, Figueiro M, Garg S, Cohen LW, Reed D, Williams CS, et al. Effect of home-based light treatment on persons with dementia and their caregivers. Light Res Technol. 2015:47(2):161-76. https://doi.org/10.1177/14 77153513517255.

80. Figueiro MG, Hunter CM, Higgins P, Hornick T, Jones GE, Plitnick B, et al. Tailored lighting intervention for persons with dementia and caregivers living at home. Sleep Health. 2015;1(4):322-30. https://doi.org/10.1016/j. sleh.2015.09.003.

81. McCurry SM, Pike KC, Vitiello MV, Logsdon RG, Larson EB, Teri L. Increasing walking and bright light exposure to improve sleep in community-dwelling persons with Alzheimer's disease: results of a randomized, controlled trial. J Am Geriatr Soc. 2011;59(8):1393-402. https://doi.org/10.1111/j.1532-5415.2 011.03519.x

82. Van De Water AT, Holmes A, Hurley DA. Objective measurements of sleep for non-laboratory settings as alternatives to polysomnography-a systematic review. J Sleep Res. 2011;20(1pt2):183-200. https://doi.org/1 0.1111/j.1365-2869.2009.00814.x.

83. Sivertsen B, Omvik S, Havik OE, Pallesen S, Bjorvatn B, Nielsen GH, et al. A comparison of actigraphy and polysomnography in older adults treated for chronic primary insomnia. Sleep. 2006;29(10):1353-8. https://doi.org/10.1 093/sleep/29.10.1353.

84. Toften S, Pallesen S, Hrozanova M, Moen F, Grønli J. Validation of sleep stage classification using non-contact radar technology and machine learning (Somnofy ${ }^{\circledR}$ ). Sleep Med Elsevier. 2020;75:54-61. https://doi.org/10.1 016/j.sleep.2020.02.022.

85. Linjakumpu TA, Hartikainen SA, Klaukka TJ, Koponen HJ, Hakko HH, Viilo KM, et al. Sedative drug use in the home-dwelling elderly. Ann Pharmacother. 2004;38(12):2017-22. https://doi.org/10.1345/aph.1E067.

86. Husebo BS, Strand LI, Moe-Nilssen R, Husebo SB, Snow AL, Ljunggren AE. Mobilization-observation-behavior-intensity-dementia pain scale (MOBID): development and validation of a nurse-administered pain assessment tool for use in dementia. J Pain Symptom Manag. 2007;34(1):67-80. https://doi. org/10.1016/j.jpainsymman.2006.10.016.

87. Sloane PD, Williams CS, Mitchell CM, Preisser JS, Wood W, Barrick AL, et al. Highintensity environmental light in dementia: effect on sleep and activity. J Am Geriatr Soc. 2007:55(10):1524-33. https:/doi.org/10.1111/j.1532-5415.2007.01358x.

88. Gentili A, Weiner DK, Kuchibhatla M, Edinger JD. Factors that disturb sleep in nursing home residents. Aging Clin Exp Res. 1997;9(3):207-13. https://doi. org/10.1007/BF03340151.

89. Grelotti DJ, Kaptchuk TJ. Placebo by proxy. BMJ. 2011;343(aug11 2):d4345. https://doi.org/10.1136/bmj.d4345.

90. Bierman A, Klein TR, Rea MS. The Daysimeter: a device for measuring optical radiation as a stimulus for the human circadian system. Meas Sci Technol. 2005;16(11):2292-9. https://doi.org/10.1088/0957-0233/16/11/023.

\section{Publisher's Note}

Springer Nature remains neutral with regard to jurisdictional claims in published maps and institutional affiliations. 